\title{
Control Strategy for a Grid-Connected Inverter under Unbalanced Network Conditions-A Disturbance Observer-Based Decoupled Current Approach
}

\author{
Emre Ozsoy $^{1}$ (D), Sanjeevikumar Padmanaban ${ }^{1, *}$ (D), Lucian Mihet-Popa ${ }^{2}$ (), Viliam Fedák ${ }^{3}$, \\ Fiaz Ahmad ${ }^{4}$ (D), Rasool Akhtar ${ }^{4}$ (D) and Asif Sabanovic ${ }^{4}$ \\ 1 Department of Electrical and Electronics Engineering, University of Johannesburg, \\ Auckland Park 2006, South Africa; eemreozsoy@yahoo.co.uk \\ 2 Faculty of Engineering, Østfold University College, Kobberslagerstredet 5, \\ 1671 Krakeroy-Fredrikstad, Norway; lucian.mihet@hiof.no \\ 3 Department of Electrical Engineering \& Mechatronics, Technical University of Kosice, Rampová 1731/7, \\ 04001 Košice, Džung'a-Džung'a, Slovakia; viliam.fedak@tuke.sk \\ 4 Mechatronics Engineering, Faculty of Engineering and Natural Sciences, Sabancı University, \\ Istanbul 34956, Turkey; fiazahmad@sabanciuniv.edu (F.A.); akhtar@sabanciuniv.edu (R.A.); \\ asif@sabanciuniv.edu (A.S.) \\ * Correspondence: sanjeevi_12@yahoo.co.in; Tel.: +27-79-219-9845
}

Received: 17 June 2017; Accepted: 10 July 2017; Published: 22 July 2017

\begin{abstract}
This paper proposes a new approach on the novel current control strategy for grid-tied voltage-source inverters (VSIs) with circumstances of asymmetrical voltage conditions. A standard grid-connected inverter (GCI) allows the degree of freedom to integrate the renewable energy system to enhance the penetration of total utility power. However, restrictive grid codes require that renewable sources connected to the grid must support stability of the grid under grid faults. Conventional synchronously rotating frame dq current controllers are insufficient under grid faults due to the low bandwidth of proportional-integral (PI) controllers. Hence, this work proposes a proportional current controller with a first-order low-pass filter disturbance observer (DOb). The proposed controller establishes independent control on positive, as well as negative, sequence current components under asymmetrical grid voltage conditions. The approach is independent of parametric component values, as it estimates nonlinear feed-forward terms with the low-pass filter DOb. A numerical simulation model of the overall power system was implemented in a MATLAB/Simulink (2014B, MathWorks, Natick, MA, USA). Further, particular results show that double-frequency active power oscillations are suppressed by injecting appropriate negative-sequence currents. Moreover, a set of simulation results provided in the article matches the developed theoretical background for its feasibility.
\end{abstract}

Keywords: power control; power electronics; pulse width modulation inverters; disturbance observer; grid connected system; grid stability; distorted voltage

\section{Introduction}

The rapid penetration of renewable energy sources (RESs) connected to the grid and distribution systems with power electronic converter topologies has changed the expected grid requirements to guarantee an appropriate performance under grid faults. In addition to the performance and reliability of the system under power electronic circuits in normal conditions, stability and grid support under grid faults are crucial due to restrictive grid code requirements [1,2]. Moreover, stability and reliability of the grid-connected inverter (GCI) under grid voltage faults must be considered for microgrid applications [3-8] with battery storage systems $[9,10]$. 
In particular, the most common fault type in electrical networks is unbalanced voltage conditions, which can easily occur in any voltage sags, and cause double-frequency power oscillations. In addition to requiring a positive sequence of active power $(\mathrm{P})$ and reactive power $(\mathrm{Q})$ injection by RESs through the GCI, these oscillations must be compensated for by injecting appropriate negative-sequence current sets. However, this aim cannot be realized by using conventional methods.

Proportional-integral (PI) controller-based vector control methods for GCI structures considering balanced voltage conditions are given in [11-13]. These methods decouple grid currents into P and Q generating components, and the PI current controllers achieve stable operation. However, this popular structure is fragile under voltage problems due to a low bandwidth of the PI controllers.

One of the first contributions related to the control of GCIs under unbalanced voltages is given in $[14,15]$, by using decoupled PI control of positive- and negative-sequence dq frames. This structure is also known as the double synchronous reference frame (DSRF) method, and is used by many researchers [16,17]. Proportional-resonant (PR) $[18,19]$ controllers are also extensively used for GCIs, which feed forward a resonant controller tuned at double the grid frequency. Direct power control methods $[20,21]$ control the required power without additional inner current loops. The method given in [22] gives an enhanced operation of decoupled DSRF (DDSRF) operation by using feed-forwarded resonant controllers. Model-based predictive control $[23,24]$ methods minimize the cost function by predicting the future current and power components of the GCI under an unbalanced voltage operation.

The decoupled control of synchronously rotating positive- and negative-sequence dq currents, as given in [14,15], is an effective method for the control of GCIs. However, this method suffers from simultaneously dissipating active and reactive power oscillating components. An instantaneous power theory calculations-based independent $\mathrm{P}$ and $\mathrm{Q}$ control strategy is given in [25], by proposing different current reference calculations depending on the power requirements. A robust power flow algorithm, which is based on the disturbance rejection control algorithm, is given in [26]. These methods given in [23-26] can independently dissipate $P$ and $Q$ double-frequency oscillations. However, the shape and magnitude of non-sinusoidal injected currents highly increase current harmonics in the system, which limits the effectiveness of these methods.

Three-phase four-leg inverters can generate sinusoidal voltage waveforms in a wide range of nonlinear operating conditions for more sensitive loads, such as for data transfer and military purposes, as they can also issue power quality requirements $[27,28]$. However, an additional phase-leg and inductance complicates the circuit and reduces the overall efficiency.

Grid synchronization is of great importance for robust control of GCIs; fast and accurate estimation of grid voltage parameters is essential to operate under grid faults. Different Phase Locked Loop (PLL) algorithms are available in the literature, aiming to operate under grid voltage problems [29-32]. It was assumed in this study that symmetrical positive- and negative-sequence component decomposition of the grid voltage was properly realized, such as is given in [33] under grid faults.

A disturbance observer (DOb)-based controller is a simple and robust structure that estimates external disturbances and uncertainties; thus the effect of disturbances and uncertainties are suppressed [34]. Estimated disturbances and system uncertainties are fed forward to the inner control loop; thus the robustness of the system is obtained. An additional external controller could be cascaded to achieve the desired performance goals, such as power and/or speed in electrical systems, as the $\mathrm{DOb}$ controls uncertain plant and removes the effect of external disturbances in the inner control loop.

Doubly fed induction generator (DFIG)-based wind turbines are also very fragile under grid voltage problems $[7,8,35-38]$, and it can be considered that problem solution techniques applied to DFIG applications can be utilized in GCI applications. DOb-based current controllers are applied to DFIGs and GCIs in $[39,40]$ by considering robustness against parameter variations under balanced voltage sets. However, this method must be carefully tuned to suppress double-frequency oscillations. This study modeled the grid dynamic model in synchronously rotating, symmetrical positive- and negative-sequence dq frames. Therefore, decoupled positive- and negative-sequence dq current components were independently controlled by achieving robust control under grid voltage faults. 
In addition to the availability of simultaneous positive- and negative-sequence current injection, the proposed method was not affected by other external disturbances and uncertainties, such as grid impedance variations.

Integral terms in conventional PI controllers must be carefully tuned to prevent unwanted overshoots for a wide range of operations. In addition, windup effects of the integrator must be considered for real-time systems. Instead of conventional PI controllers and fed-forwarded parameter-dependent cross-coupling terms, proposed proportional controllers with a low-pass filter $\mathrm{DOb}$ are sufficient for robust operation, as the $\mathrm{DOb}$ accurately estimates and feeds forward uncertain terms. The control structure is simple and can be applied in real-time systems.

The main contribution of this study is a proportional decoupled current controller with a fed-forwarded low-pass filter $\mathrm{DOb}$, which satisfies positive-sequence power requirements by independently controlling negative-sequence currents. The main advantage of this $\mathrm{P}+\mathrm{DOb}$ current controller is to bring freedom from the sensitivity of the controllers with regard to variations in the grid parameters during operation for various reasons. Other methods outlined in [23-26] simultaneously control $\mathrm{P}$ and $\mathrm{Q}$ oscillations, as well as robustly satisfy positive-sequence power requirements. However, these methods inject non-sinusoidal currents to the grid at the instant of unbalanced voltage conditions. Conventional PI controllers are sensitive to parameter variations and anti-windup effects. This is the first reported study for a decoupled dq current control structure by using symmetrical component decomposition and estimating the disturbances with the DOb concept. The study was implemented on a Matlab/Simulink (2014B, MathWorks, Natick, MA, USA) simulation platform.

\section{Dynamic Model}

The equivalent circuit of the GCI is given in Figure 1 in the abc frame. The system was connected to the grid with respective grid resistance and inductance values. The dynamic model could be rewritten as either stationary or in the synchronously rotating dq frame, according to the given equivalent circuit.

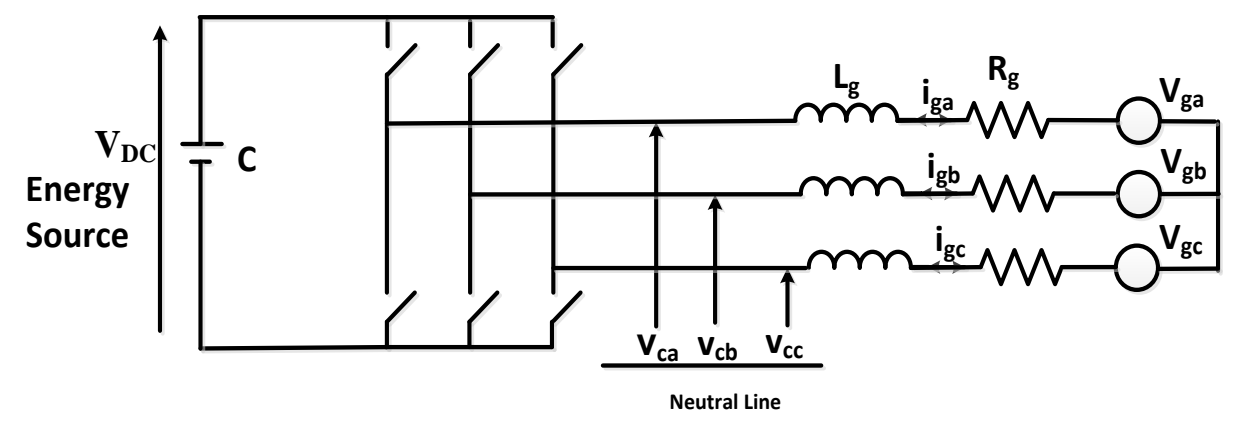

Figure 1. Equivalent circuit of the GCI in the abc frame.

The three-phase electrical variables, such as current, voltage, etc., could be indicated in several different types of reference frames [41,42]. Two orthogonal, synchronously rotating components in the $\mathrm{dq}$ frame are sufficient if a balanced system representation is required. However, they are insufficient in the case of an unbalanced system representation, and respective positive- and negative-sequence components must be presented.

The dynamical model could be arranged in the orthogonal frame of reference associated with positive and negative symmetrical components of the grid voltage, where positive sequence $(\mathrm{dq})+$ frames are composed of balanced voltages, while unbalanced voltage components generate negative sequence (dq) - frames, as is given in Figure 2. 


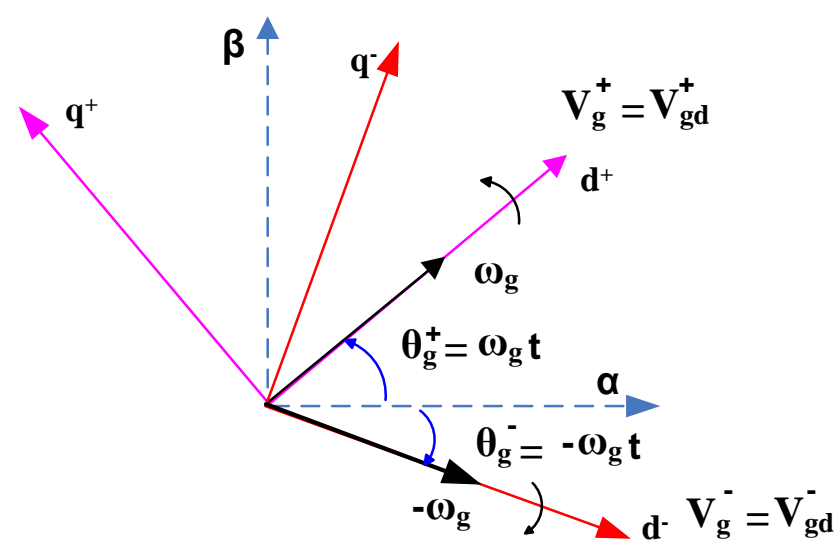

Figure 2. Orthogonal (dq)+ and (dq) - frames of references.

The current equation in symmetrical $(\mathrm{dq})+$ and $(\mathrm{dq})-$ frames can be written as

$$
L_{g} \frac{d i_{g}}{d t}=v_{s}-R_{g} i_{g}+L i_{g}-v_{g}
$$

where

$$
\begin{aligned}
& \mathrm{i}_{\mathrm{g}}^{\mathrm{T}}=\left[\begin{array}{cccc}
\mathrm{i}_{\mathrm{gd}}^{+} & \mathrm{i}_{\mathrm{gq}}^{+} & \mathrm{i}_{\mathrm{gd}}^{-} & \mathrm{i}_{\mathrm{gq}}^{-}
\end{array}\right], \mathrm{v}_{\mathrm{g}}^{\mathrm{T}}=\left[\begin{array}{llll}
\mathrm{v}_{\mathrm{gd}}^{+} & \mathrm{v}_{\mathrm{gq}}^{+} & \mathrm{v}_{\mathrm{gd}}^{-} & \mathrm{v}_{\mathrm{gq}}^{-}
\end{array}\right], \mathrm{v}_{\mathrm{s}}^{\mathrm{T}}=\left[\begin{array}{llll}
\mathrm{v}_{\mathrm{sd}}^{+} & \mathrm{v}_{\mathrm{sq}}^{+} & \mathrm{v}_{\mathrm{sd}}^{-} & \mathrm{v}_{\mathrm{sq}}^{-}
\end{array}\right], \\
& L_{g}=\operatorname{diag}\left[\begin{array}{llll}
L_{g} & L_{g} & L_{g} & L_{g}
\end{array}\right], R_{g}=\operatorname{diag}\left[\begin{array}{llll}
R_{g} & R_{g} & R_{g} & R_{g}
\end{array}\right], \\
& \mathrm{L}=\left[\begin{array}{cccc}
0 & \omega_{\mathrm{g}} \mathrm{L}_{\mathrm{g}} & 0 & 0 \\
\omega_{\mathrm{g}} \mathrm{Lg}_{\mathrm{g}} & 0 & 0 & 0 \\
0 & 0 & 0 & \omega_{\mathrm{g}} \mathrm{Lg}_{\mathrm{g}} \\
0 & 0 & \omega_{\mathrm{g}} \mathrm{Lg}_{\mathrm{g}} & 0
\end{array}\right]
\end{aligned}
$$

The terms $i_{g}$ and $v_{g}$, represent the grid currents and voltages in the synchronously rotating dq frame. The term $v_{s}$ is the GCI output voltage. The terms $R_{g}$ and $L_{g}$ represent the grid resistances and inductances. All diagonal elements of the $\mathrm{L}_{\mathrm{g}}$ and $\mathrm{R}_{\mathrm{g}}$ matrix for the symmetrical systems are equal. The meaning of the $+/$ - superscripts are for $(\mathrm{dq})+$ and $(\mathrm{dq})$ - rotating frames, respectively. The $d / q$ subscript refers to $\mathrm{dq}$ rotating frames. The term $\omega_{\mathrm{g}}$ is the grid electrical speed. The rotating frame is aligned with the $\mathrm{d}$ axis, and $\mathrm{v}_{\mathrm{q}}=0$. The line currents are assumed to be measured, and the GCI-output generated voltage is known. The GCI circuit can be written as is given below:

$$
\begin{gathered}
\frac{d i_{g}}{d t}=L_{g}^{-1} v_{s}-L_{g}^{-1} R_{g} i_{g}+L_{g}^{-1} L_{g}-L_{g}^{-1} v_{g}, \\
\varepsilon_{g}=i_{g}^{r e f}-i_{g}
\end{gathered}
$$

where $\varepsilon_{\mathrm{g}}^{\mathrm{T}}=\left[\begin{array}{cccc}\varepsilon_{\mathrm{gd}}^{+} & \varepsilon_{\mathrm{gq}}^{+} & \varepsilon_{\mathrm{gd}}^{-} & \varepsilon_{\mathrm{gq}}^{-}\end{array}\right]$is the error of control performance. If Equation (5) is inserted into the derivative of Equation (6), the error dynamics can be given as

$$
\frac{\mathrm{d} \varepsilon_{\mathrm{g}}}{\mathrm{dt}}=\frac{\mathrm{di}_{\mathrm{g}}^{\mathrm{ref}}}{\mathrm{dt}}-\mathrm{L}_{\mathrm{g}}^{-1} \mathrm{v}_{\mathrm{s}}+\mathrm{L}_{\mathrm{g}}^{-1} \mathrm{R}_{\mathrm{g}} \mathrm{i}_{\mathrm{g}}-\mathrm{L}_{\mathrm{g}}^{-1} \mathrm{Li}_{\mathrm{g}}+\mathrm{L}_{\mathrm{g}}^{-1} \mathrm{v}_{\mathrm{g}},
$$

The closed-loop error equation is given as follows:

$$
\frac{\mathrm{d} \varepsilon_{\mathrm{g}}}{\mathrm{dt}}+\mathrm{k}_{\mathrm{g}} \varepsilon_{\mathrm{g}}=0
$$


The term $\mathrm{k}_{\mathrm{g}}^{\mathrm{T}}=\operatorname{diag}\left[\begin{array}{llll}\mathrm{k}_{\mathrm{gd}}^{+} & \mathrm{k}_{\mathrm{gq}}^{+} & \mathrm{k}_{\mathrm{gd}}^{-} & \mathrm{k}_{\mathrm{gq}}^{-}\end{array}\right]$is a positive controller gain. The error of control performance $\varepsilon_{\mathrm{g}}$ is defined by asymptotic convergence to zero. The definition of convergence speed is dependent on the value of $\mathrm{kg}_{\mathrm{g}}$ coefficients. If Equation (7) is inserted into Equation (8), applied generated voltages to the $\mathrm{GCI}$ are written as follows:

$$
\mathrm{L}_{\mathrm{g}}^{-1} \mathrm{v}_{\mathrm{s}}=\frac{\mathrm{di}_{\mathrm{g}}^{\mathrm{ref}}}{\mathrm{dt}}+\mathrm{L}_{\mathrm{g}}^{-1} \mathrm{R}_{\mathrm{g}} \mathrm{i}_{\mathrm{g}}-\mathrm{L}_{\mathrm{g}}^{-1} \mathrm{Li}_{\mathrm{g}}+\mathrm{L}_{\mathrm{g}}^{-1} \mathrm{v}_{\mathrm{g}}+\mathrm{k}_{\mathrm{g}} \varepsilon_{\mathrm{g}}
$$

The grid inductance base value, $\mathrm{Lg}$, is insensitive to disturbances. Thus, voltages applied for the GCI are written as below:

$$
\mathbf{v}_{\mathrm{s}}^{\text {ref }}=\underbrace{\mathrm{Lg}_{\mathrm{g}}\left(\frac{\mathrm{di}_{\mathrm{g}}^{\mathrm{ref}}}{\mathrm{dt}}+\mathrm{L}_{\mathrm{g}}^{-1} \mathrm{R}_{\mathrm{g}} \mathrm{i}_{\mathrm{g}}-\mathrm{L}_{\mathrm{g}}^{-1} \mathrm{Li}_{\mathrm{g}}+\mathrm{L}_{\mathrm{g}}^{-1} \mathrm{v}_{\mathrm{g}}\right)}_{\mathrm{f}_{\mathrm{g}}}+\mathrm{Lgk}_{\mathrm{g}} \varepsilon_{\mathrm{g}},
$$

The terms $\mathrm{f}_{\mathrm{g}}^{\mathrm{T}}=\left[\begin{array}{llll}\mathrm{f}_{\mathrm{gd}}^{+} & \mathrm{f}_{\mathrm{gq}}^{+} & \mathrm{f}_{\mathrm{gd}}^{-} & \mathrm{f}_{\mathrm{gq}}^{-}\end{array}\right]$are nonlinear, and an accurate determination of grid and GCI parameters is required to define these terms; this is impractical and $f_{g}$ is considered as a disturbance.

Necessary and sufficient conditions for asymptotic stability of the control structure must satisfy the following conditions of the Lyapunov candidate function:

$$
\mathrm{V}(0)=0, \mathrm{~V}>0 \text { and } \dot{\mathrm{V}}<0,
$$

The term $\mathrm{V}$ is the Lyapunov candidate function. The Lyapunov function and time derivative of the Lyapunov function can be selected, as given below, to prove the asymptotic stability:

$$
\mathrm{V}=\frac{1}{2} \varepsilon_{\mathrm{g}}^{2}, \frac{\mathrm{dV}}{\mathrm{dt}}=\varepsilon_{\mathrm{g}} \frac{\mathrm{d} \varepsilon_{\mathrm{g}}}{\mathrm{dt}},
$$

The first condition for Lyapunov stability is satisfied for $\mathrm{V}(0)=0$ The second condition for Lyapunov stability $(\mathrm{V}>0)$ is valid for all real $\varepsilon$ values. Finally, the third condition $(\dot{\mathrm{V}}<0)$ can be satisfied by inserting Equation (8) into the time derivative of the Lyapunov candidate function.

$$
\frac{\mathrm{dV}}{\mathrm{dt}}=-\varepsilon_{\mathrm{g}} k_{\mathrm{g}} \varepsilon_{\mathrm{g}}
$$

It is obvious from Equation (13) that the time derivative of the Lyapunov candidate function is negative for positive, definite $\mathrm{k}_{\mathrm{g}}$ values. Thus, necessary and sufficient conditions for the asymptotic stability of the controller structure are satisfied.

\subsection{First-Order Low-Pass Filter Disturbance Observer}

The term $\mathrm{f}_{\mathrm{g}}$ can be estimated by modifying the voltage equations. If Equation (8) is inserted into Equation (9), determination of the grid voltage is possible to enforce the desired control performance in the current loop. The disturbance terms are considered as bounded, and are defined by $\dot{f}_{g}=0$ with unknown initial conditions [43]. System inputs and outputs $\left(v_{s}\right.$ and $\left.i_{g}\right)$ are considered to be known or measured.

$$
\mathrm{f}_{\mathrm{g}}=\mathrm{v}_{\mathrm{s}}-\mathrm{Lg}_{\mathrm{g}} \frac{\mathrm{di}_{\mathrm{g}}}{\mathrm{dt}}
$$

The first-order low-pass filter DOb is applied to Equation (14) in the s domain, as is given below:

$$
\hat{\mathrm{f}}_{\mathrm{g}}=\mathrm{T}\left(\mathrm{v}_{\mathrm{s}}-\mathrm{sLg}_{\mathrm{g}} \mathrm{i}_{\mathrm{g}}\right)
$$


where $\mathrm{T}^{\mathrm{T}}=\operatorname{diag}\left[\begin{array}{llll}\frac{\mathrm{g}_{\mathrm{d}}^{+}}{\mathrm{s}+\mathrm{g}_{\mathrm{d}}^{+}} & \frac{\mathrm{g}_{\mathrm{q}}^{+}}{\mathrm{s}+\mathrm{g}_{\mathrm{q}}^{+}} & \frac{\mathrm{g}_{\mathrm{d}}^{-}}{\mathrm{s}+\mathrm{g}_{\mathrm{d}}^{-}} & \frac{\mathrm{g}_{\mathrm{q}}^{-}}{\mathrm{s}+\mathrm{g}_{\mathrm{q}}^{-}}\end{array}\right]$.

The term $s$ is the Laplace operator. The coefficients $g_{d}$ and $g_{q}$ are the cut-off frequency gains. To simplify the implementation of the DOb, Equation (15) can be rewritten as is given below.

$$
\hat{\mathrm{f}}_{\mathrm{g}}=\mathrm{T}\left(\mathrm{v}_{\mathrm{s}}-\mathrm{Lg}_{\mathrm{g}} \mathrm{i}_{\mathrm{g}}\right)+\mathrm{gL} \mathrm{L}_{\mathrm{g}}
$$

where $\mathrm{g}=\operatorname{diag}\left[\begin{array}{cccc}\mathrm{g}_{\mathrm{d}}^{+} & \mathrm{g}_{\mathrm{q}}^{+} & \mathrm{g}_{\mathrm{d}}^{-} & \mathrm{g}_{\mathrm{q}}^{-}\end{array}\right]$. The block diagram of the DOb could be drawn as is given in Figure 3.

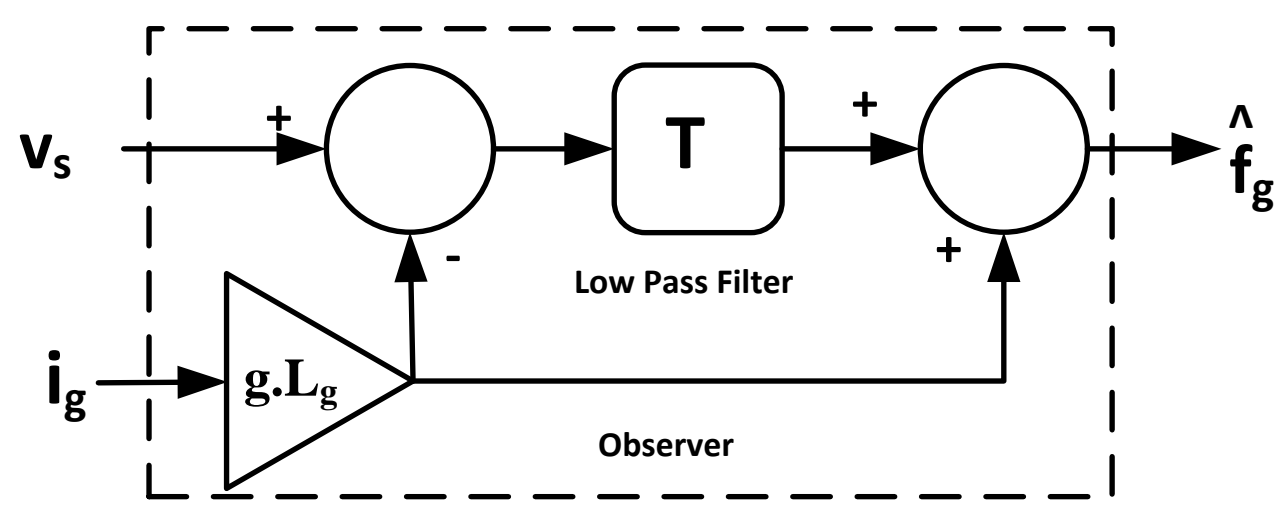

Figure 3. Disturbance observer (DOb) block diagram.

The final grid current error equations are given by

$$
\frac{\mathrm{d} \varepsilon_{\mathrm{g}}}{\mathrm{dt}}+\mathrm{k}_{\mathrm{g}} \varepsilon_{\mathrm{g}}=\mathrm{f}_{\mathrm{g}}-\hat{\mathrm{f}}_{\mathrm{g}}
$$

It can be stated from Equation (17) that the right-hand-side tends towards zero, as is given below. The optimal selection of the low-pass filter parameter is to set $[\mathrm{T}]=\operatorname{diag}[1]$ in the frequency range in which disturbance is expected. The bandwidth of the DOb should be as high as possible, so the disturbance error can converge to zero in a wide range of frequencies. The DOb compensation error will converge to zero in practical terms with a proper selection of the cut-off frequency [43]. This estimated disturbance plays a very critical role in the controller structure as a feed-forward term, and does not influence the stability of the closed-loop controller structure with the properly selected cut-off frequencies. Because of the effectiveness of the feed-forward disturbance term, the integral action is not required in the closed-loop structure. Therefore, the proportional controller with a positive definite $\mathrm{kg}_{\mathrm{g}}$ value is sufficient for the controller error to converge to zero in a finite time. As a result, the proposed controller structure is more robust and simple, compared to conventional PI controllers, as it estimates and feeds forward the disturbance terms without the integral part of the controller.

\subsection{Instantaneous Power Equations}

The instantaneous powers associated with unbalanced current and voltage components can be written in the following form [44], with multiplication of the double-frequency oscillating components.

$$
\left[\begin{array}{l}
\mathrm{P}(\mathrm{t}) \\
\mathrm{Q}(\mathrm{t})
\end{array}\right]=\left[\begin{array}{l}
\mathrm{P}_{\mathrm{g} 0} \\
\mathrm{Q}_{\mathrm{g} 0}
\end{array}\right]+\left[\begin{array}{c}
\mathrm{P}_{\mathrm{sc} 2} \\
\mathrm{Q}_{\mathrm{sc} 2}
\end{array}\right] \cos \left(2 \omega_{\mathrm{g}} \mathrm{t}\right)+\left[\begin{array}{c}
\mathrm{P}_{\mathrm{ss} 2} \\
\mathrm{Q}_{\mathrm{ss} 2}
\end{array}\right] \sin \left(2 \omega_{\mathrm{g}} \mathrm{t}\right),
$$


where

$$
\begin{aligned}
& {\left[\begin{array}{l}
\mathrm{P}_{\mathrm{g} 0} \\
\mathrm{Q}_{\mathrm{g} 0}
\end{array}\right]=1.5\left[\begin{array}{cccc}
\mathrm{v}_{\mathrm{gd}}^{+} & \mathrm{v}_{\mathrm{gq}}^{+} & \mathrm{v}_{\mathrm{gd}}^{-} & \mathrm{v}_{\mathrm{gd}}^{-} \\
\mathrm{v}_{\mathrm{gq}}^{+} & -\mathrm{v}_{\mathrm{gd}}^{+} & \mathrm{v}_{\mathrm{gq}}^{-} & -\mathrm{v}_{\mathrm{gd}}^{-}
\end{array}\right]\left[\begin{array}{c}
\mathrm{i}_{\mathrm{gd}}^{+} \\
\mathrm{i}_{\mathrm{gq}}^{+} \\
\mathrm{i}_{\mathrm{gd}}^{-} \\
\mathrm{i}_{\mathrm{gq}}^{-}
\end{array}\right],} \\
& {\left[\begin{array}{c}
\mathrm{P}_{\mathrm{sc} 2} \\
\mathrm{Q}_{\mathrm{sc} 2}
\end{array}\right]=1.5\left[\begin{array}{cccc}
\mathrm{v}_{\mathrm{gd}}^{-} & \mathrm{v}_{\mathrm{gq}}^{-} & \mathrm{v}_{\mathrm{gd}}^{+} & \mathrm{v}_{\mathrm{gq}}^{+} \\
\mathrm{v}_{\mathrm{gq}}^{-} & -\mathrm{v}_{\mathrm{gd}}^{-} & \mathrm{v}_{\mathrm{gq}}^{+} & -\mathrm{v}_{\mathrm{gd}}^{+}
\end{array}\right]\left[\begin{array}{c}
\mathrm{i}_{\mathrm{gd}}^{+} \\
\mathrm{i}_{\mathrm{gq}}^{+} \\
\mathrm{i}_{\mathrm{gd}}^{-} \\
\mathrm{i}_{\mathrm{gq}}^{-}
\end{array}\right],} \\
& {\left[\begin{array}{c}
\mathrm{P}_{\mathrm{ss} 2} \\
\mathrm{Q}_{\mathrm{ss} 2}
\end{array}\right]=1.5\left[\begin{array}{cccc}
\mathrm{v}_{\mathrm{gq}}^{-} & -\mathrm{v}_{\mathrm{gd}}^{-} & -\mathrm{v}_{\mathrm{gq}}^{+} & \mathrm{v}_{\mathrm{gd}}^{+} \\
-\mathrm{v}_{\mathrm{gd}}^{-} & -\mathrm{v}_{\mathrm{gq}}^{-} & \mathrm{v}_{\mathrm{gd}}^{+} & \mathrm{v}_{\mathrm{gq}}^{+}
\end{array}\right]\left[\begin{array}{c}
\mathrm{i}_{\mathrm{gd}}^{+} \\
\mathrm{i}_{\mathrm{gq}}^{+} \\
\mathrm{i}_{\mathrm{gd}}^{-} \\
\mathrm{i}_{\mathrm{gq}}^{-}
\end{array}\right],}
\end{aligned}
$$

The terms, $\mathrm{P}_{\mathrm{g} 0}$ and $\mathrm{Q}_{\mathrm{g} 0}$ are fundamental instantaneous $\mathrm{P}$ and $\mathrm{Q}$ components, which consist of positive- and negative-sequence power equations, while the terms $P_{\mathrm{sc} 2}-P_{\mathrm{ss} 2}$ and $Q_{\mathrm{sc} 2}-\mathrm{Q}_{\mathrm{ss} 2}$ are four pulsating terms, which are the result of asymmetrical network conditions. The maximum four variables $\left(\mathrm{i}_{\mathrm{gd}}^{+} \quad \mathrm{i}_{\mathrm{gq}}^{+} \quad \mathrm{i}_{\mathrm{gd}}^{-} \quad \mathrm{i}_{\mathrm{gq}}^{-}\right.$) could be controlled to achieve the $\mathrm{P}_{\mathrm{g} 0}$ and $\mathrm{Q}_{\mathrm{g} 0}$ requirements and compensate for the $\mathrm{P}_{\mathrm{sc} 2}-\mathrm{P}_{\mathrm{ss} 2}$ and $\mathrm{Q}_{\mathrm{sc} 2}-\mathrm{Q}_{\mathrm{ss} 2}$ oscillating components. Thus, $\mathrm{P}$ and $\mathrm{Q}$ oscillations cannot be compensated for simultaneously in positive- and negative-sequence dq frames [44]. It is necessary to calculate an appropriate set of current references to ensure a constant value of $P$ is absorbed or injected by the GCI under balanced and unbalanced voltage conditions. These $\mathrm{P}_{\mathrm{g} 0}$ and $\mathrm{Q}_{\mathrm{g} 0}$ requirements and the $\mathrm{P}_{\mathrm{sc} 2}-\mathrm{P}_{\mathrm{ss} 2}$ oscillation compensation can be addressed by using the following expression:

$$
\left[\begin{array}{c}
P_{g 0} \\
\mathrm{Q}_{\mathrm{g} 0} \\
\mathrm{P}_{\mathrm{sc} 2} \\
\mathrm{P}_{\mathrm{ss} 2}
\end{array}\right]=1.5\left[\begin{array}{cccc}
\mathrm{v}_{\mathrm{gd}}^{+} & \mathrm{v}_{\mathrm{gq}}^{+} & \mathrm{v}_{\mathrm{gd}}^{-} & \mathrm{v}_{\mathrm{gq}}^{-} \\
\mathrm{v}_{\mathrm{gq}}^{+} & -\mathrm{v}_{\mathrm{gd}}^{+} & \mathrm{v}_{\mathrm{gq}}^{-} & -\mathrm{v}_{\mathrm{gd}}^{-} \\
-\mathrm{v}_{\mathrm{gd}}^{-} & \mathrm{v}_{\mathrm{gq}}^{-} & \mathrm{v}_{\mathrm{gd}}^{+} & \mathrm{v}_{\mathrm{gq}}^{+} \\
\mathrm{v}_{\mathrm{gq}}^{-} & -\mathrm{v}_{\mathrm{gd}}^{-} & -\mathrm{v}_{\mathrm{gq}}^{+} & \mathrm{v}_{\mathrm{gd}}^{+}
\end{array}\right]\left[\begin{array}{c}
\mathrm{i}_{\mathrm{gd}}^{+} \\
\mathrm{i}_{\mathrm{gq}}^{+} \\
\mathrm{i}_{\mathrm{gd}}^{-} \\
\mathrm{i}_{\mathrm{gq}}^{-}
\end{array}\right]
$$

Equation (22) defines how positive-sequence grid current controllers achieve $\mathrm{P}$ and $\mathrm{Q}$ requirements, while negative-sequence current controllers can compensate for the $\mathrm{P}$ oscillations depending on the negative-sequence current injection strategy.

The proposed scheme is depicted in Figure 4. If zero $\mathrm{i}_{\mathrm{gd}}^{-}$and $\mathrm{i}_{\mathrm{gd}}^{-}$references are chosen, injected currents towards the grid are sinusoidal; this supports power quality requirements. If a zero $\mathrm{P}_{\mathrm{sc} 2}-\mathrm{P}_{\mathrm{ss} 2}$ reference selection is selected, double-frequency oscillating power components can be compensated for by injecting negative-sequence currents towards the grid. The proportional current controllers are sufficient to track the desired current requirements with accurately estimated disturbance terms. The block diagram in Figure 3 is used to estimate disturbance terms. An online Second Order Generalized Integrator (SOGI)-based symmetrical component estimation is achieved with the method given in [33]. PLL structures separately calculate the symmetrical voltage phase and angle. It is assumed that symmetrical component decomposition of the voltage and currents is perfectly estimated, and an accurate PLL voltage phase and angle estimation is achieved. 


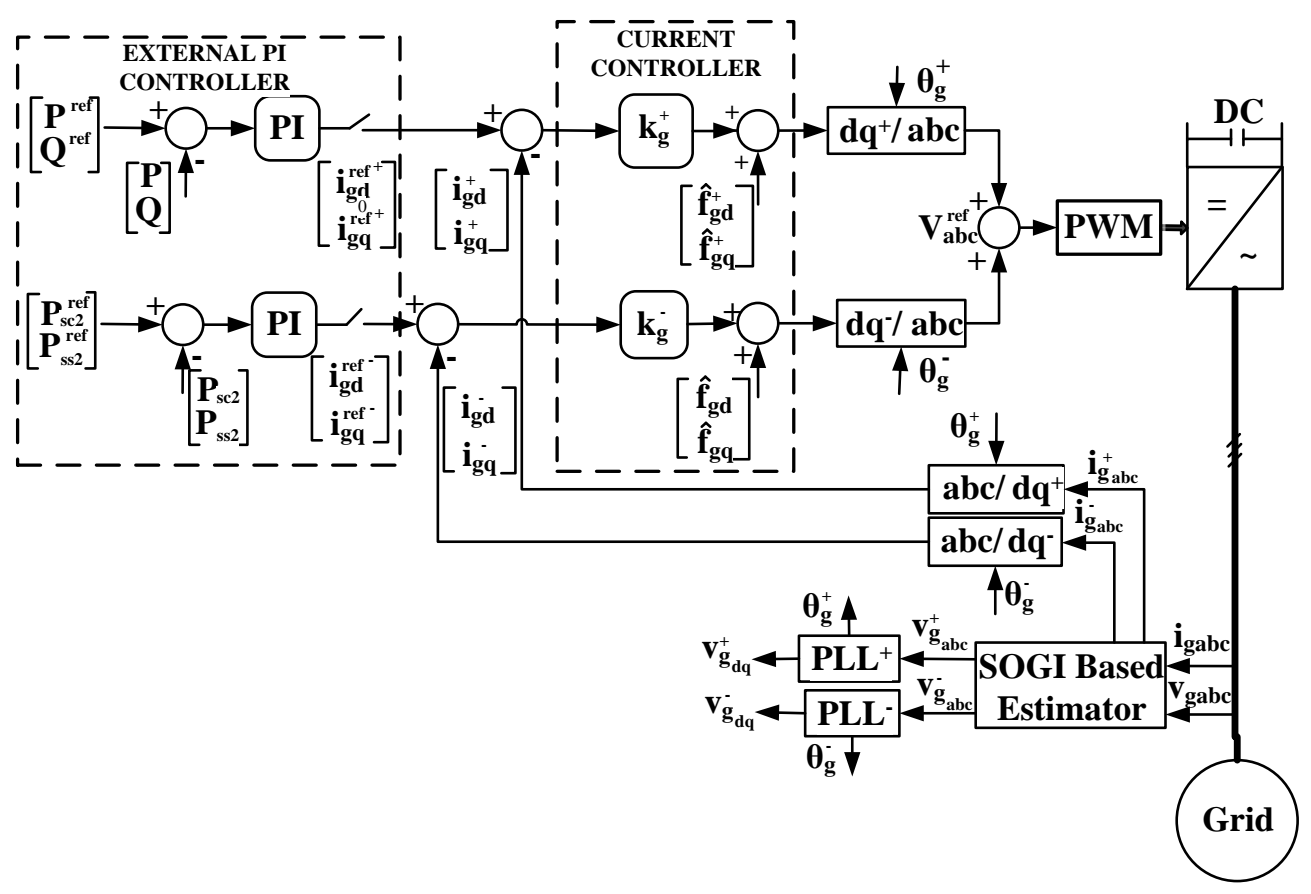

Figure 4. Proposed controller structure.

\section{Simulation Results}

Figure 5 depicts the simulation circuit implemented in MATLAB/Simulink using the SimPowerSystem tool. The GCI was connected to a transmission system, and all necessary parameters for the simulation are given in Table 1. Four different simulations were implemented to validate the proposed controller structure. The first simulation demonstrated the deteriorated current and power waveforms under unbalanced voltage conditions with the positive-sequence controller, without enabling the negative-sequence controller (Simulation A). The dual-current controller with the enabled negative-sequence current controller enforced negative-sequence currents to zero in the second simulation (Simulation B). The third simulation enforced double-frequency $\mathrm{P}_{\mathrm{sc} 2}-\mathrm{P}_{\mathrm{ss} 2}$ power oscillations to zero. In addition, the dynamic performance of positive-sequence controllers was demonstrated by applying appropriate dq current steps (Simulation C). Finally, the fourth simulation compared the performance of conventional PI controllers to DOb-based current controllers (Simulation D).

Table 1. Parameters used in simulations.

\begin{tabular}{ccc}
\hline Symbol & Quantity & Unit \\
\hline Grid Connnected Inverter (GCI) DC Voltage & 750 & $\mathrm{~V}$ \\
Nominal GCI Current & 500 & $\mathrm{~A}$ \\
Nominal GCI Power & 350 & $\mathrm{KVA}$ \\
Switching Frequency & 10 & $\mathrm{kHz}$ \\
Lg Filter of GCI & 0.25 & $\mathrm{mH}$ \\
X/R Ratio of Grid & 7 & - \\
$\mathrm{K}_{\mathrm{P}}(+) / \mathrm{K}_{\mathrm{P}}(-)$ & 20 & - \\
$\mathrm{g}_{\mathrm{d}}$ & 500 & $\mathrm{rad}$ \\
\hline
\end{tabular}

The DC voltage was kept constant at $750 \mathrm{~V}$ to reduce the harmonic stress in the currents, which meant RESs were connected to the DC bus, and could inject required power to the grid at any instant of the simulation. Reference of $\mathrm{i}_{\text {gd }}^{+}$was kept at $75 \mathrm{~A}$, meaning that the injection of currents were applied towards the grid. Reference of $\mathrm{i}_{\mathrm{gq}}^{+}$was kept at $0 \mathrm{~A}$ to ensure a zero reactive power injection. The applied steps at different instants of Simulation A and B were given as follows: 
$0.20-0.27 \mathrm{~s}: 30 \%$ unbalanced voltage condition was generated on phase- $\mathrm{A}$ in the grid.

$0.30-0.35 \mathrm{~s}: \mathrm{i}_{\mathrm{gd}}^{+}$reference step was applied from 75 to $150 \mathrm{~A}$.

$0.38-0.43 \mathrm{~s}: \mathrm{i}_{\mathrm{gq}}^{+}$reference step was applied from 0 to $50 \mathrm{~A}$.

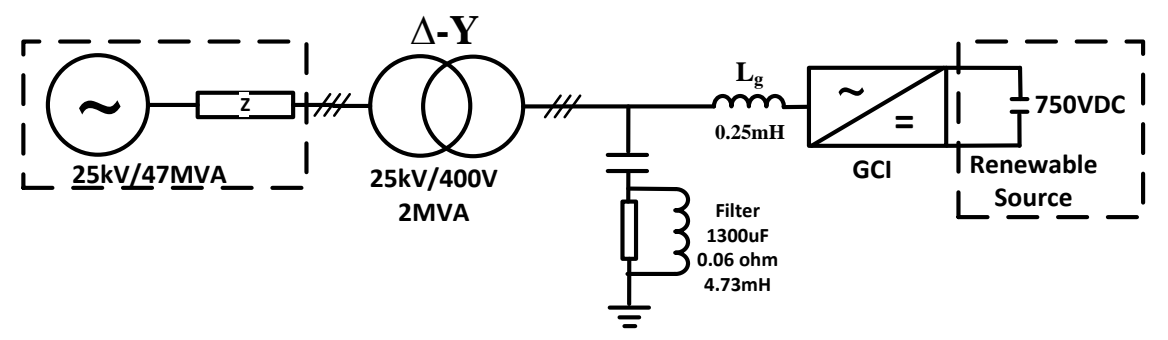

Figure 5. Simulation circuit.

Figure 6 shows the first simulation results (Simulation A) with the disabled negative-sequence controller. A $30 \%$ unbalanced voltage on phase-A between 0.20 and $0.27 \mathrm{~s}$ was applied, which is shown in Figure 6a. Sinusoidal grid currents (Figure $6 \mathrm{~b}$ ) show that the sinusoidal shape deteriorated without the negative-sequence current controller. Figure $6 c$ shows the respective dq axis current references that changed $\mathrm{P}_{\mathrm{g}}$ and $\mathrm{Q}_{\mathrm{g}}$ properly. Respective $\mathrm{i}_{\mathrm{gd}}^{+}$and $\mathrm{i}_{\mathrm{gq}}^{+}$step-response tests are shown in Figure $6 \mathrm{~d}$. The performance criteria was satisfied with the DOb-based current controllers without any steady-state error or overshoot. Double-grid frequency power oscillations exist under unbalanced voltages, and could be dissipated by injecting negative-sequence currents. Figure 7 shows the uncontrolled $\mathrm{i}_{\mathrm{gd}}^{-}$and $\mathrm{i}_{\mathrm{gq}}^{-}$currents and the resultant oscillation $\mathrm{P}_{\mathrm{ss} 2}$ and $\mathrm{P}_{\mathrm{sc} 2}$ components that were the root cause of double-frequency oscillations.

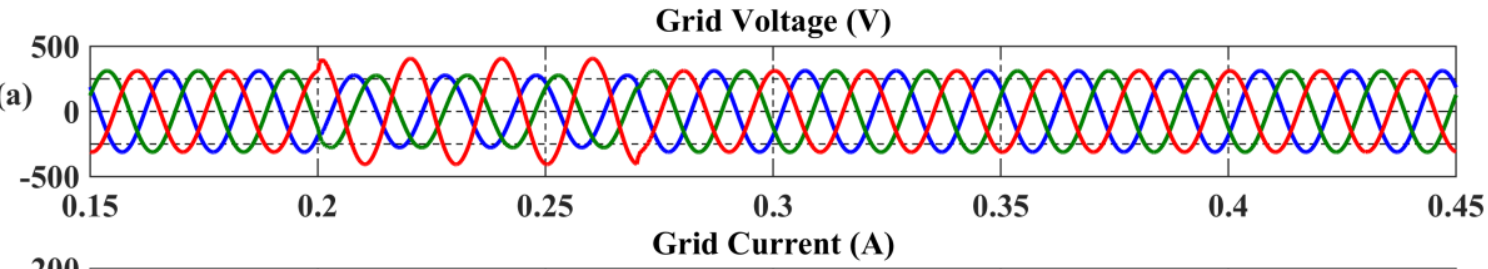

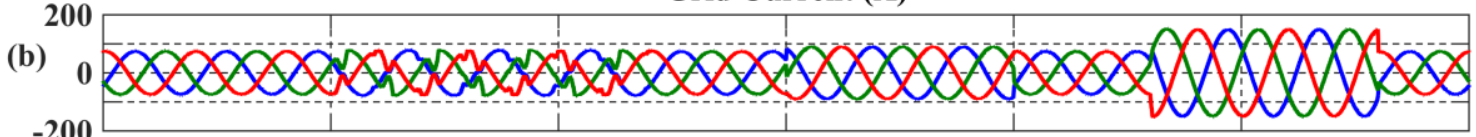

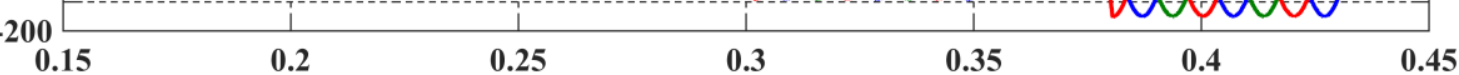

Active and Reactive Power (kW)

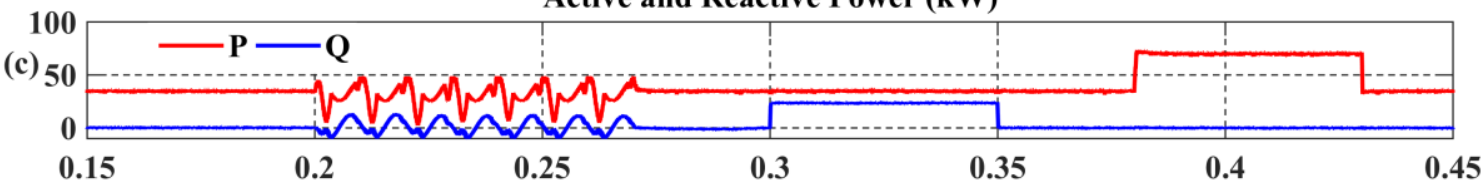

Positive Sequence dq-Axis Currents (A)

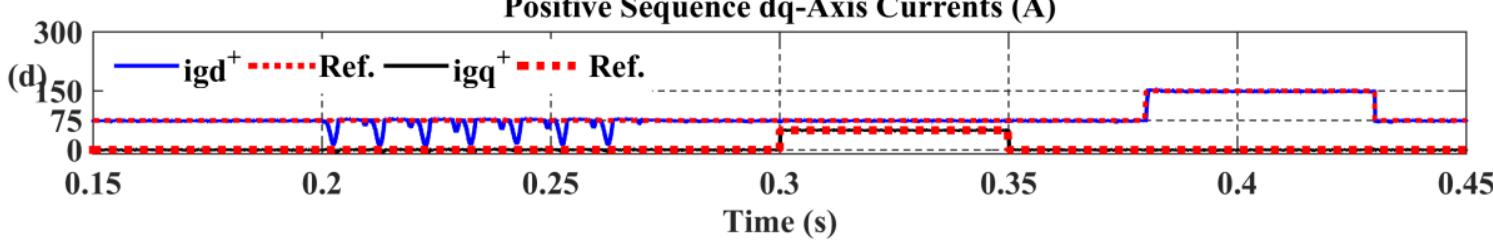

Figure 6. Simulation A results without dual positive- and negative-sequence controllers: (a) grid voltage (V) (red: phase-A, blue: phase-B, green: phase-C); (b) grid currents (A) (red: phase-A, blue: phase- $\mathrm{B}$, green: phase-C); (c) $\mathrm{P}_{\mathrm{g}}(\mathrm{kW})$ and $\mathrm{Q}_{\mathrm{g}}(\mathrm{kVAr})$; and (d) positive-sequence dq axis currents $(\mathrm{A})$. 
(a)
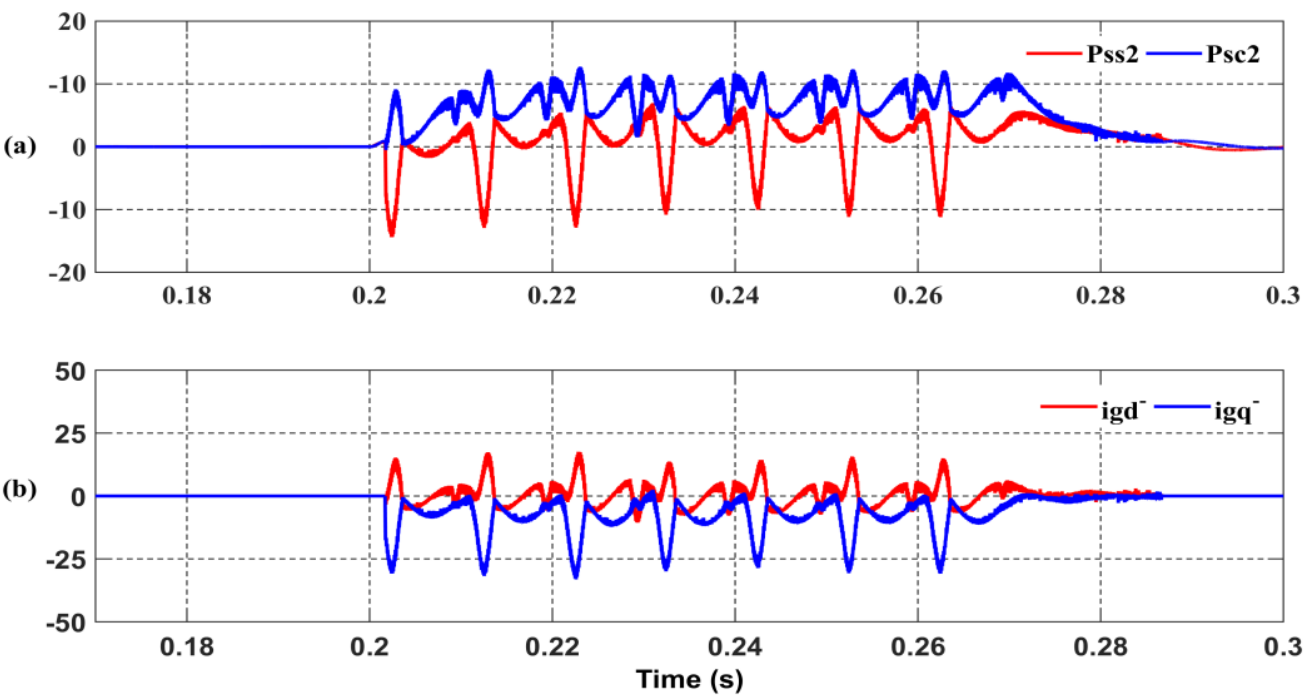

Figure 7. Simulation A results without dual positive- and negative-sequence controllers: $(\mathbf{a}) \mathrm{P}_{\mathrm{ss} 2}(\mathrm{~kW})$ and $\mathrm{P}_{\mathrm{sc} 2}(\mathrm{~V})$ components, and $(\mathbf{b}) \mathrm{i}_{\mathrm{gd}}^{-}(\mathrm{A})$ and $\mathrm{i}_{\mathrm{gq}}^{-}(\mathrm{A})$.

Similarly, Figure 8 shows the second simulation results (Simulation B) with dual positive- and negative-sequence current controller results. The negative-sequence controller was only enabled when an unbalanced voltage existed in the grid because it was observed in simulations that enabling the negative-sequence controller in balanced voltage conditions unnecessarily deteriorated the dynamic performance of the overall system [45]. Thus, a simple logic condition was added in the simulation to enable or disable the negative-sequence controller, depending on the negative-sequence voltage level. Figure $8 \mathrm{~b}$ shows the balanced grid current sets with a zero negative-sequence grid current injection. Figure $8 \mathrm{c}$ shows that double-frequency $\mathrm{P}$ oscillations still existed due to the $\mathrm{P}_{\mathrm{ss} 2}$ and $\mathrm{P}_{\mathrm{sc} 2}$ components.

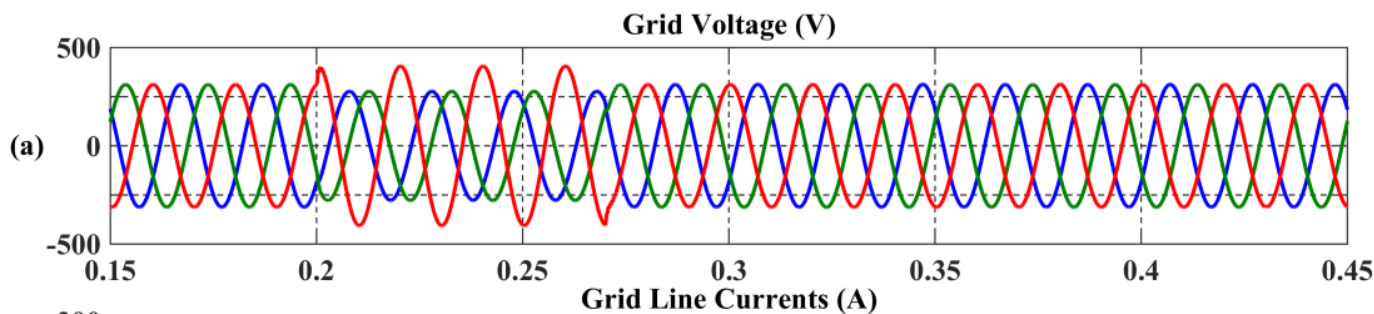

(b)
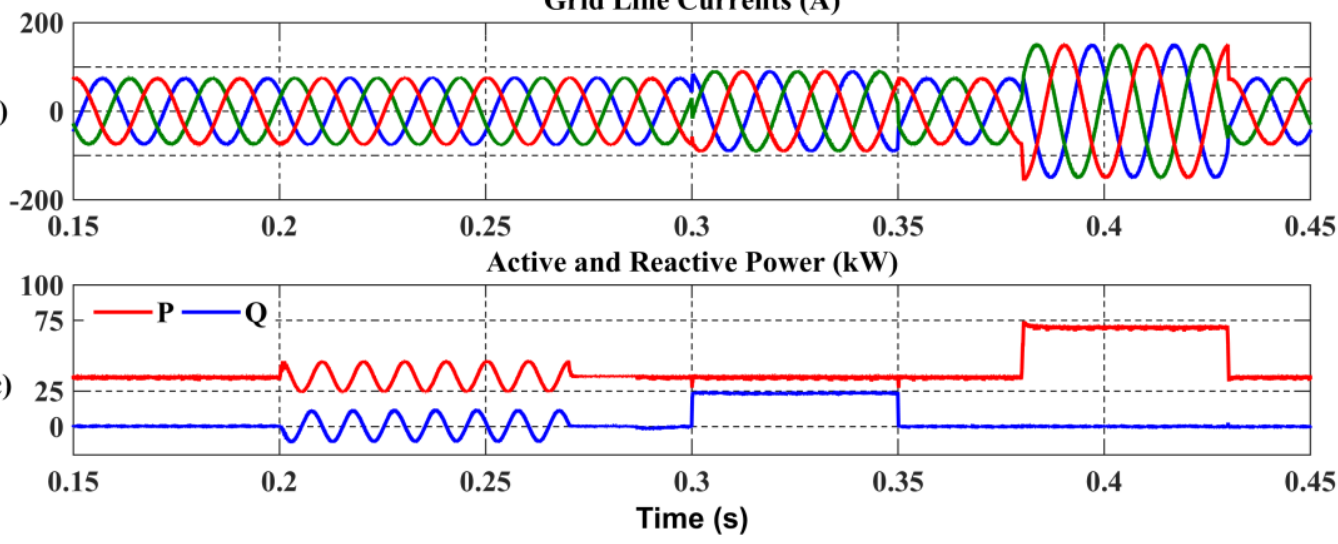

Figure 8. Simulation $B$ results with dual positive- and negative-sequence controllers: (a) grid voltage (V) (red: phase-A, blue: phase-B, green: phase-C); (b) grid currents (A) (red: phase-A, blue: phase-B, green: phase-C); and (c) $\mathrm{P}_{\mathrm{g}}(\mathrm{kW})$ and $\mathrm{Q}_{\mathrm{g}}(\mathrm{kVAr})$. 
Figure 9a shows the positive-sequence currents, where the performance of the current trajectory was satisfied. Figure $9 b$ shows $f_{g d}$ and the estimated $\hat{f}_{g d}^{+}$. The term $\mathrm{f}_{g d}^{+}$was calculated with dynamic equations and compared with $\hat{\mathrm{f}}_{\mathrm{gd}}^{+}$. The mean value of $\hat{\mathrm{f}}_{\mathrm{gd}}^{+}$was equal to $\mathrm{f}_{\mathrm{gd}}^{+}$, which proved that the term $\hat{\mathrm{f}}_{\mathrm{gd}}^{+}$was accurately estimated. Similarly, Figure $9 \mathrm{c}$ shows both the parameters $\mathrm{f}_{\mathrm{gq}}^{+}$and the estimated $\hat{\mathrm{f}}_{\mathrm{gq}}^{+}$ pointing out that the term $\hat{\mathrm{f}}_{\mathrm{gq}}^{+}$was accurately estimated.

(a)
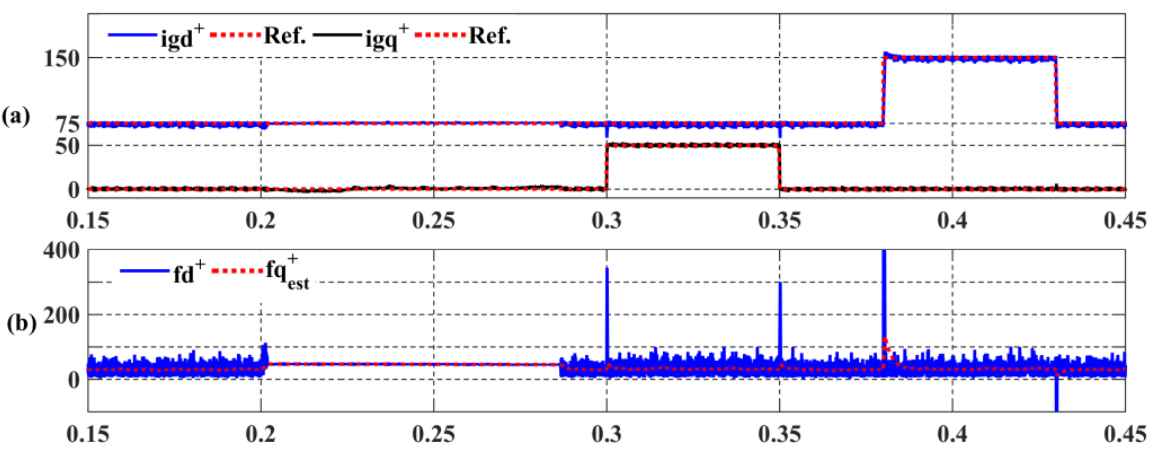

(c)

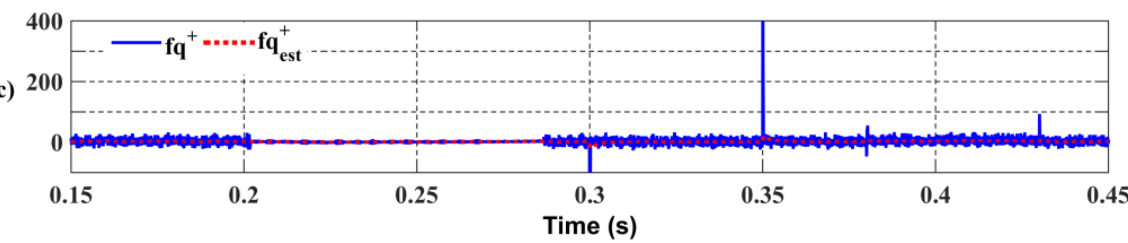

Figure 9. Simulation $\mathrm{B}$ results with dual positive- and and negative-sequence controllers:

(a) positive-sequence dq axis currents $(A),(\mathbf{b}) \mathrm{f}_{\mathrm{gd}}^{+}$and $\hat{\mathrm{f}}_{\mathrm{gd}}^{+}(\mathrm{V})$, and $(\mathbf{c}) \mathrm{f}_{\mathrm{gq}}^{+}$and $\hat{\mathrm{f}}_{\mathrm{gq}}^{+}(\mathrm{V})$.

Negative-sequence current components were enforced to zero at the instant of unbalanced voltage conditions, and deteriorated grid current waveforms were dissipated, as shown in Figure 8b. Double-frequency power oscillations could not be removed without an appropriate injection of negative-sequence currents. Figure 10a shows that the negative-sequence currents could be controlled at zero references. Figure $10 \mathrm{~b}, \mathrm{c}$ shows the negative sequence of the parameters $\mathrm{f}_{\mathrm{gd}}^{-}-\mathrm{f}_{\mathrm{gq}}^{-}$and the estimated $\hat{\mathrm{f}}_{\mathrm{gd}}^{-}-\hat{\mathrm{f}}_{\mathrm{gq}}^{-}$. The mean values of the estimated components were equal to the calculated terms, which proved that the estimated terms were accurately estimated.
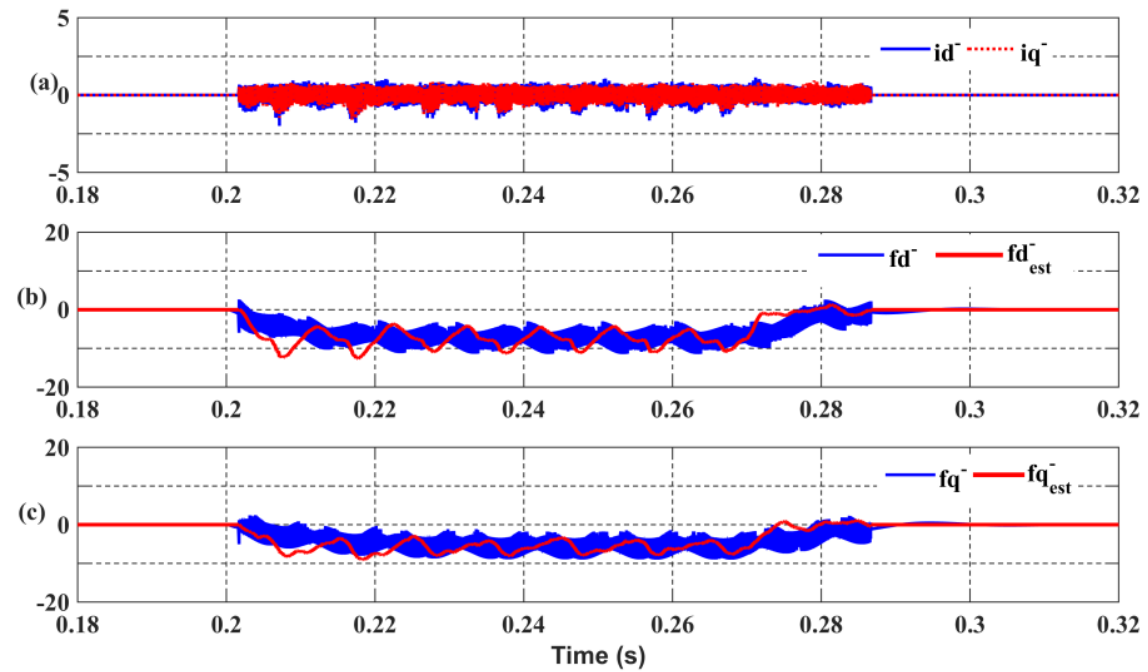

Figure 10. Simulation $B$ results with dual positive- and negative-sequence controllers: (a) negative sequence dq axis currents $(A),(b) f_{g d}^{-}$and $\hat{f}_{g d}^{-}(V)$, and $(c) f_{g q}^{-}$and $\hat{f}_{g q}^{-}(V)$. 
Figures 11-13 show the third simulation results for dissipating the $\mathrm{P}_{\mathrm{sc} 2}-\mathrm{P}_{\mathrm{ss} 2}$ power oscillations (Simulation C). External PI controllers with a reference of $P_{\mathrm{sc} 2}-P_{\mathrm{ss} 2}=0$ were enabled, as shown in Figure 4. A 30\% unbalanced voltage was generated between 0.2 and $0.27 \mathrm{~s}$ (Figure 11a). Similar to for Simulation $B$, the negative-sequence controller was enabled at predefined unbalanced voltage levels. The reference value of $\mathrm{i}_{\mathrm{gd}}^{+}$was kept at $75 \mathrm{~A}$, and $\mathrm{i}_{\mathrm{gq}}^{+}$was kept at zero. Figure $11 \mathrm{c}$ shows that double-frequency $\mathrm{P}$ oscillations were dissipated under the unbalanced voltage operation, and that $\mathrm{P}$ and $Q$ could be independently controlled under balanced conditions.

(a)

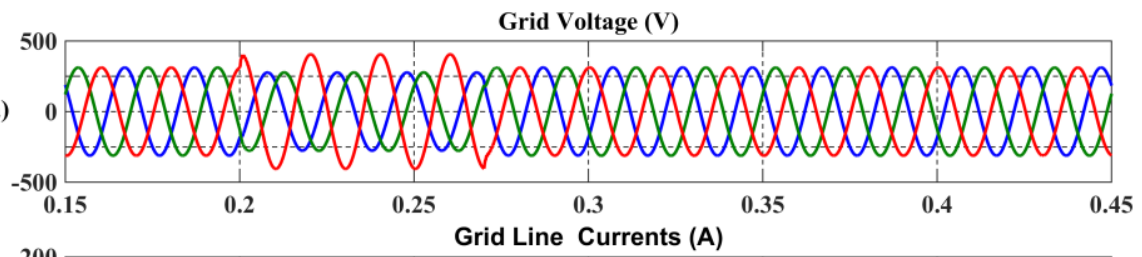

(b)

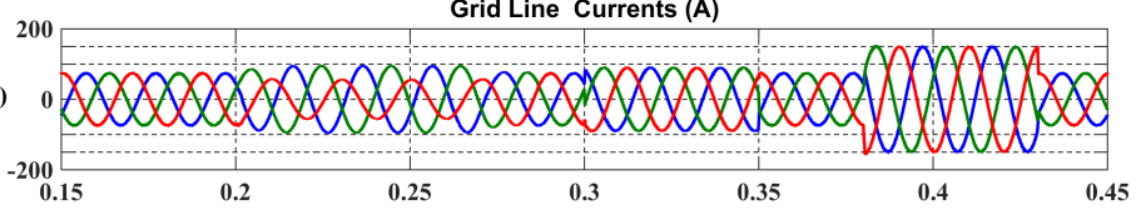

(c)

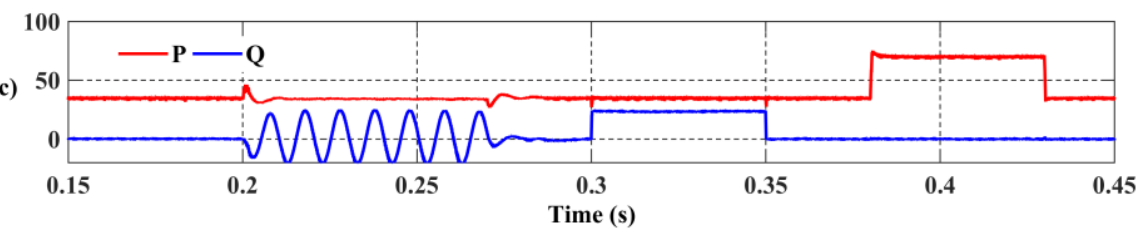

Figure 11. Simulation $C$ results with external $P_{s s 2}-P_{s c 2}$ controllers: (a) grid voltage (V) (red: phase-A, blue: phase- $B$, green: phase-C); (b) grid currents (A) (red: phase-A, blue: phase- $B$, green: phase-C); and (c) $P_{g}(k W)$ and $Q_{g}(k V A r)$.
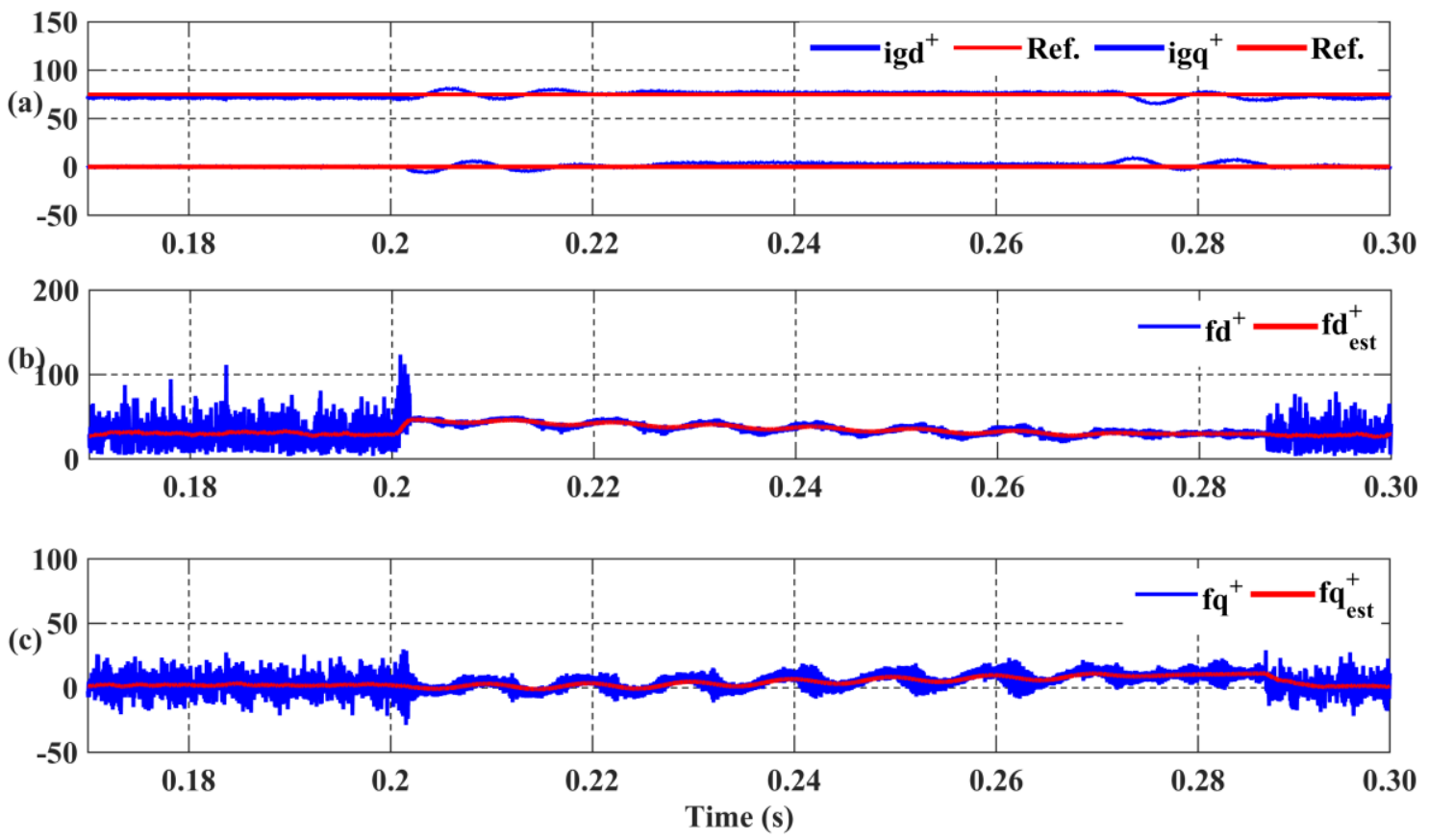

Figure 12. Simulation $C$ results with external $\mathrm{P}_{\mathrm{ss} 2}-\mathrm{P}_{\mathrm{sc} 2}$ controllers: (a) grid voltage $(\mathrm{V})$; (b) grid currents (A); and (c) positive-sequence dq axis currents (A). 
(a)

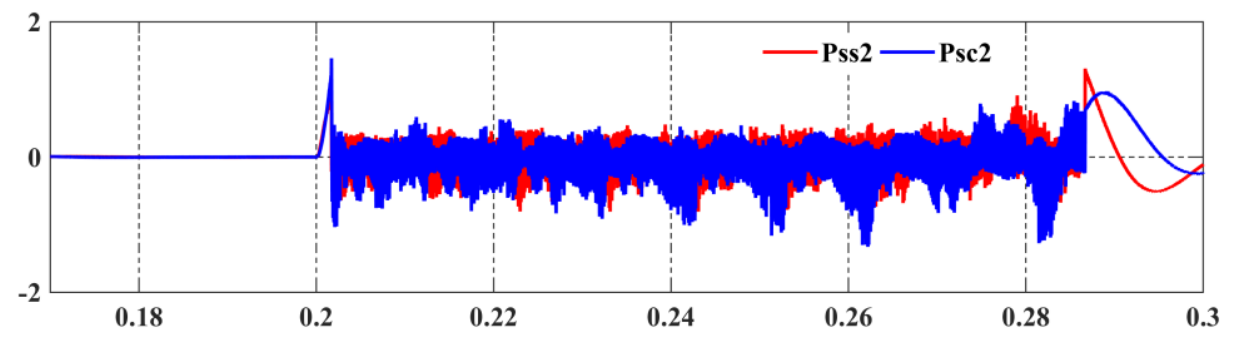

(b)

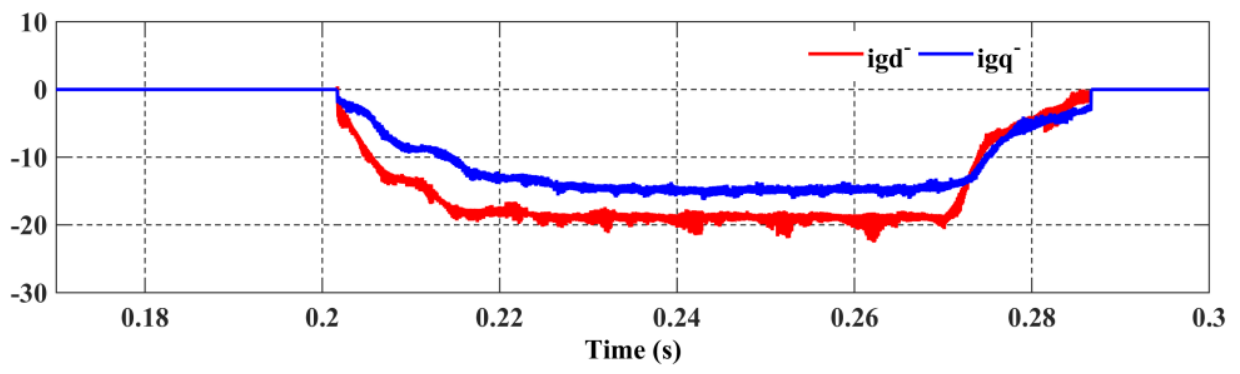

Figure 13. Simulation $C$ results with external $P_{s s 2}-P_{s c 2}$ controllers: (a) $P(k W)$ and $Q(k V A r),(b)$ grid currents (A).

Figure 12 shows that positive-sequence currents could follow their respective references at the instant of the unbalanced voltage generation. Figure $12 b, c$ shows that the calculated $f_{g}$ and estimated $\hat{\mathrm{f}}_{\mathrm{g}}^{+}$terms were equal, which meant that $\hat{\mathrm{f}}_{\mathrm{gd}}^{+}$and $\hat{\mathrm{f}}_{\mathrm{gq}}^{+}$were accurately estimated.

The oscillating components $\mathrm{P}_{\mathrm{sc} 2}-\mathrm{P}_{\mathrm{ss} 2}$ were enforced to zero with external PI controllers. PI controller gains could easily be determined with trial and error methods $\left(K_{p}=1.1\right.$ and $\left.K_{I}=5.2\right)$. It can be noted from Equation (22) that oscillating $\mathrm{P}_{\mathrm{sc} 2}$ and $\mathrm{P}_{\mathrm{ss} 2}$ components could be compensated for by internal $\mathrm{i}_{\mathrm{gd}}^{-}$and $\mathrm{i}_{\mathrm{gq}}^{-}$controllers, respectively. Double-frequency oscillations were removed on $\mathrm{P}$ by enforcing the $\mathrm{P}_{\mathrm{sc} 2}-\mathrm{P}_{\mathrm{ss} 2}$ components to zero, as can be seen in Figure 13a, and Figure 13b shows the resultant injected $\mathrm{i}_{\text {gd }}^{-}$and $\mathrm{i}_{\text {gq }}^{-}$components.

Finally, the proposed DOb-based current controller was compared with the conventional PI controller. The performance comparison seemed to be equivalent under a balanced operation, depending on the controller's proportional and integral gains. In addition, it is difficult to comment whether either the conventional PI or proposed DOb-based current controller was better in performance under balanced voltage conditions. However, the DOb-based current controller showed a better dynamic performance, and did not cause any steady-state error in positive-sequence currents under unbalanced voltage conditions; this is shown in previous plots (Figures 11 and 12). The conventional PI controller resulted in steady-state current and power errors under unbalanced voltage conditions. This problem is also stated in [45], in that symmetrical decomposition methods degrade dynamic performance and may cause steady-state errors in PI controllers. It was shown in Simulation D that the aforementioned problem exists in constructed simulation platforms with $\mathrm{k}_{\mathrm{p}}=20$ and $\mathrm{k}_{1}=5$ values. The dynamic performance seemed equivalent under a balanced operation; steady-state error plots under an unbalanced voltage operation are demonstrated in Figure 14. Figure 14a,b shows that the $i_{\text {gd }}^{+}$and $\mathrm{i}_{\mathrm{gq}}^{+}$components could not follow the respective trajectories under an unbalanced operation, and if a longer unbalanced voltage operation was applied, the steady-state error would have slowly increased to unacceptable values. A similar behavior also existed in the P component, as shown in Figure 14c. 
(a)

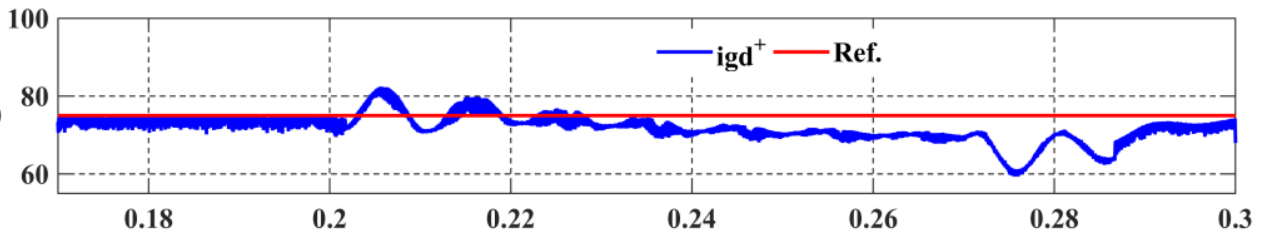

(b)

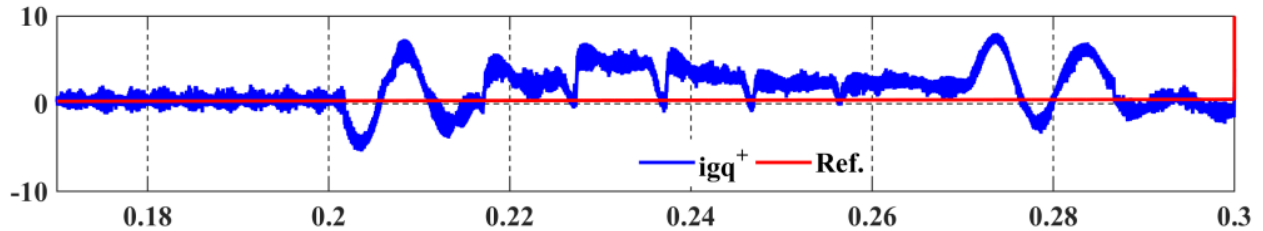

(c)

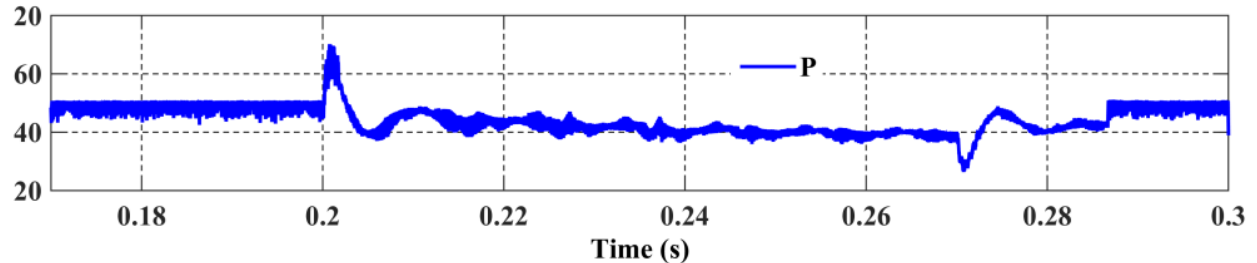

Figure 14. Simulation $D$ results with the conventional PI controller: (a) $i_{g d}^{+}(A),(b) i_{g q}^{+}(A)$, and (c) $\mathrm{P}(\mathrm{kW})$.

\section{Conclusions}

The objective of this paper was to investigate a novel current controller that was based on a low-pass filter $\mathrm{DOb}$, to provide a precise control of currents under unbalanced grid voltage conditions for a grid-tied inverter. The GCI was modeled in the symmetrical synchronous reference frames, and estimated disturbance parameters were fed to current controllers. P and Q were defined by using the instantaneous power theory, and double-frequency $\mathrm{P}_{\mathrm{ss} 2}$ and $\mathrm{P}_{\mathrm{sc} 2}$ pulsations were removed under a full propagation cycle. PI and proposed DOb-based proportional current controllers were compared, and it was demonstrated that conventional PI controllers may cause steady-state errors under an asymmetrical grid voltage operation. Numerical simulation results also proved that the methods applied were able to compensate for the double-frequency power oscillations for the grid-tied inverter application, which means that the objective was achieved. The proposed current controller seems to be a valid alternative solution for GCIs under unbalanced conditions. Hopefully, the results presented will form a basis for diagnosis methods regarding the control techniques of GCIs under unbalanced network conditions. Due to the fact that the study was limited to the simulation results, instead the effect of real components, more research is certainly needed.

Author Contributions: Emre Ozsoy and Sanjeevikumar Padmanaban developed the proposed control strategy for the grid-connected system under distorted conditions. Emre Ozsoy, Sanjeevikumar Padmanaban, Lucian Mihet-Popa, Fiaz Ahmad, Rasool Akhtar and Asif Sabanovic were involved in further development of the study and in the implementation strategy. Sanjeevikumar Padmanaban, Lucian Mihet-Popa, Viliam Fedák and Asif Sabanovic contributed expertise in the grid-connected system for the verification of theoretical concepts and validation of obtained results. All authors contributed to and were involved in framing the final version of the full research article in its current form.

Conflicts of Interest: The authors declare no conflict of interest.

\section{References}

1. Basso, T.S.; DeBlasio, R. IEEE 1547 series of standards: interconnection issues. IEEE Trans. Power Electron. 2004, 19, 1159-1162. [CrossRef]

2. Markiewicz, H.; Klajn, A. Voltage Disturbances Standard EN50160_Voltage Characteristics in Public Distribution Systems; Copper Development Association: Hertfordshire, UK, 2004. 
3. Sridhar, V.; Umashankar, S.; Sanjeevikumar, P. Decoupled Active and reactive power control of cascaded H-Bridge PV-Inverter for grid connected applications. In Lecture Notes in Electrical Engineering; Springer: Berlin/Heidelberg, Germany, 2017.

4. Swaminathan, G.; Ramesh, V.; Umashankar, S.; Sanjeevikumar, P. Fuzzy Based micro grid energy management system using interleaved boost converter and three level NPC inverter with improved grid voltage quality. In Lecture Notes in Electrical Engineering; Springer: Berlin/Heidelberg, Germany, 2017.

5. Swaminathan, G.; Ramesh, V.; Umashankar, S.; Sanjeevikumar, P. Investigations of microgrid stability and optimum power sharing using Robust Control of grid tie PV inverter. In Lecture Notes in Electrical Engineering; Springer: Berlin/Heidelberg, Germany, 2017.

6. Awasthi, A.; Karthikeyan, V.; Rajasekar, S.; Sanjeevikumar, P.; Siano, P.; Ertas, A. Dual mode control of inverter to integrate solar-wind hybrid fed DC-Grid with distributed AC grid. In Proceedings of the IEEE Conference on Environment and Electrical Engineering, Florence, Italy, 7-10 June 2016.

7. Mihet-Popa, L. Current Signature Analysis as diagnosis media for incipient fault detection. J. Adv. Electr. Comput. Eng. 2007, 7, 11-16. [CrossRef]

8. Mihet-Popa, L.; Prostean, O.; Szeidert, I.; Filip, I.; Vasar, C. Fault detection methods for frequency converters fed induction machines. In Proceedings of the 12th IEEE Conference on Emerging Technologies and Factory Automation-ETFA, Patras, Greece, 25-28 September 2007; pp. 161-168.

9. Das, V.; Sanjeevikumar, P.; Karthikeyan, V.; Rajasekar, S.; Blaabjerg, F.; Pierluigi, S. Recent advances and challenges of fuel cell based power system architectures and control-A review. Renew. Sustain. Energy 2017, 73, 10-18. [CrossRef]

10. Vavilapalli, S.; Sanjeevikumar, P.; Umashankar, S.; Mihet-Popa, L. Power balancing control for grid energy storage system in PV spplications—Real time digital simulation implementation. Energies 2017, 10, 928. [CrossRef]

11. Pena, R.; Clare, J.C.; Asher, G.M. A doubly-fed induction generator using two back-to-back PWM converters and its application to variable speed wind energy system. Proc. Inst. Elect. Eng. B 1996, 143, 231-241.

12. Mihet-Popa, L.; Groza, V.; Prostean, G.; Filip, I.; Szeidert, I. Variable Speed Wind Turbines Using Cage Rotor Induction Generators Connected to the Grid. Proceeding of the IEEE Canada Electrical Power Conference, EPC 2007, Montreal, QC, Canada, 25-26 October 2007.

13. Mihet-Popa, L.; Groza, V.; Prostean, O.; Szeidert, I. Modeling and design of a grid connection control mode for a small variable-speed wind turbine system. In Proceedings of the IEEE I2MTC-International Instrumentation \& Measurement Technology Conference, Vancouver Island, BC, Canada, 12-15 May 2008; pp. 288-293.

14. Rioual, P.; Pouliquen, H.; Louis, H.P. Control of a PWM rectifier in the unbalanced state by robust voltage regulation. In Proceedings of the 5th European Conference Power Electronics Applications, Brighton, UK, 13-16 September 1993; Volume 4, pp. 8-14.

15. Song, H.S.; Nam, K. Dual current control scheme for PWM converter under unbalanced input voltage conditions. IEEE Trans. Ind. Electron. 1999, 46, 953-959. [CrossRef]

16. Suh, Y.; Tijeras, V.; Lipo, T.A. Control scheme in hybrid synchronous stationary frame for PWMAC/DC converter under generalized unbalanced operating conditions. IEEE Trans. Ind. Appl. 2006, 42, 825-835.

17. Suh, Y.; Tijeras, V.; Lipo, T.A. A control method in dq synchronous frame for PWM boost rectifier under generalized unbalanced operating conditions. In Proceedings of the IEEE 33rd Annual Power Electronics Specialists Conference, Cairns, Australia, 23-27 June 2002; Volume 3, pp. 1425-1430.

18. Teodorescu, R.; Blaabjerg, F.M.; Liserre, M.; Loh, P.C. Proportional Resonant controllers and filters for grid-connected voltage-source converters. IEE Proc.-Electr. Power Appl. 2006, 153, 750-762. [CrossRef]

19. Lascu, C.; Asiminoaei, L.; Boldea, I.; Blaabjerg, F. High performance current controller for selective harmonic compensation in active power filters. IEEE Trans. Power Electron. 2007, 22, 1826-1835. [CrossRef]

20. Serpa, L.A.; Ponnaluri, S.; Barbosa, P.M.; Kolar, J.W. A modified direct power control strategy allowing the connection of three-phase inverters to the grid through LCL filters. IEEE Trans. Ind. Appl. 2007, 43, 1388-1400. [CrossRef]

21. Vazquez, S.; Sanchez, J.A.; Carrasco, J.M.; Leon, J.I.; Galvan, E. A model-based direct power control for three-phase power converters. IEEE Trans. Ind. Electron. 2008, 55, 1647-1657. [CrossRef] 
22. Reyes, M.; Rodriguez, P.; Vazquez, S.; Luna, A.; Teodorescu, R.; Carrasco, J.M. Enhanced decoupled double synchronous reference frame current controller for unbalanced grid-voltage conditions. IEEE Trans. Power Electron. 2012, 27, 3934-3943. [CrossRef]

23. Dawei, Z.; Lie, X.; Williams, B.W. Model-based predictive direct power control of doubly fed induction generators. IEEE Trans. Power Electron. 2010, 25, 341-351. [CrossRef]

24. Cort'es, P.; Rodriguez, J.; Antoniewicz, P.; Kazmierkowski, M. Direct power control of an AFE using predictive control. IEEE Trans. Power Electron. 2008, 23, 2516-2553. [CrossRef]

25. Rodriguez, C.P.; Timbus, A.V.; Teodorescu, R.; Liserre, M.; Blaabjerg, F. Independent PQ control for distributed power generation systems under grid faults. In Proceedings of the IEEE Industrial Electronics 32nd Annual Conference IECON, Paris, France, 6-10 November 2006; pp. 5185-5190.

26. Wang, Y.; Beibei, R.; Zhong, Q.C. Robust power flow control of grid-connected inverters. IEEE Trans. Ind. Electron. 2016, 63, 6687-6897. [CrossRef]

27. Ortjohann, E.; Arturo, A.; Morton, D.; Mohd, A.; Hamsic, N.; Omari, O. Grid-forming three-phase inverters for unbalanced loads in hybrid power systems. In Proceedings of the 2006 IEEE 4th World Conference on Photovoltaic Energy Conference, Waikoloa, HI, USA, 7-12 May 2006.

28. Vechium, I.; Camblong, H.; Tapia, G.; Curea, O.; Dakyo, B. Modelling and control of four-wire voltage source inverter under unbalanced voltage condition for hybrid power system applications. In Proceedings of the 2005 European Conference on Power Electronics and Applications, Dresden, Germany, 11-14 September 2005.

29. Chung, S.K. A phase tracking system for three phase utility interface inverters. IEEE Trans. Power Electron. 2000, 15, 431-438. [CrossRef]

30. Rodriguez, P.; Pou, J.; Bergas, J.; Candela, J.; Burgos, R.P.; Boroyevich, D. Decoupled double synchronous reference frame PLL for power converters control. IEEE Trans. Power Electron. 2007, 22, 584-592. [CrossRef]

31. Rodriguez, P.; Luna, A.; Teodorescu, R.; Iov, F.; Blaabjerg, F. Fault ride-through capability implementation in wind turbine converters using a decoupled double synchronous reference frame PLL. In Proceedings of the Power Electronics and Applications European Conference, Aalborg, Denmark, 2-5 September 2007; pp. 1-10.

32. Ciobotaru, M.; Teodorescu, R.; Blaabjerg, F. A new single-phase PLL structure based on second order generalized integrator. In Proceedings of the Power Electronics Specialists Conference, Jeju, Korea, 18-22 June 2006; pp. 1-6.

33. Iravani, M.R.; Karimi-Ghartemani, M. Online estimation of steady state and instantaneous symmetrical components. IEEE Proc. Gener. Transm. Distrib. 2003, 150, 616-622. [CrossRef]

34. Ohnishi, K.; Shibata, M.; Murakami, T. Motion control for advanced mechatronics. IEEE/ASME Trans. Mechatron. 1996, 1, 56-67. [CrossRef]

35. Tamvada, K.; Umashankar, S.; Sanjeevikumar, P. Investigation of double fed induction generator behavior under Symmetrical and Asymmetrical Fault Conditions. In Lecture Notes in Electrical Engineering; Springer: Berlin/Heidelberg, Germany, 2017.

36. Tamvada, K.; Umashankar, S.; Sanjeevikumar, P. Impact of Power Quality Disturbances on Grid Connected Double Fed Induction Generator. In Lecture Notes in Electrical Engineering; Springer: Berlin/Heidelberg, Germany, 2017.

37. Tiwaria, R.; Babu, N.R.; Sanjeevikumar, P. A Review on GRID CODES-Reactive power management in power grids for Doubly-Fed Induction Generator in Wind Power application. In Lecture Notes in Electrical Engineering; Springer: Berlin/Heidelberg, Germany, 2017.

38. Kalaivani, C.; Sanjeevikumar, P.; Rajambal, K.; Bhaskar, M.S.; Mihet-Popa, L. Grid Synchronization of Seven-phase Wind Electric Generator using d-q PLL. Energies 2017, 10, 926. [CrossRef]

39. Ozsoy, E.E.; Golubovic, E.; Sabanovic, A.; Gokasan, M.; Bogosyan, S. A novel current controller scheme for doubly fed induction generators. Autom. J. Control Meas. Electron Comput. Commun. 2015, 56, 186-195. [CrossRef]

40. Ozsoy, E.E.; Golubovic, E.; Sabanovic, A.; Gokasan, M.; Bogosyan, S. Modeling and control of a doubly fed induction generator with a disturbance observer: A stator voltage oriented approach. Turk. J. Electr. Eng. Comput. Sci. 2016, 24, 961-972. [CrossRef]

41. Akagi, H.; Watanabe, E.H.; Aredes, M. Instantaneous Power Theory and Applications to Power Conditioning; John Wiley \& Sons: New York, NY, USA, 2007. 
42. Krause, P.C.; Wasynczuk, O.; Sudhoff, S.D. Analysis of Electrical Machinery and Drive Systems, 2nd ed.; John Wiley \& Sons: New York, NY, USA, 2002.

43. Sabanovic, A.; Ohnishi, K. Motion Control Systems; John Wiley \& Sons: New York, NY, USA, 2011.

44. Teodorescu, R.; Liserre, M.; Rodriguez, P. Grid Converters for Photovoltaic and Wind Power Systems; John Wiley \& Sons: New York, NY, USA, 2011.

45. Xu, L. Coordinated control of DFIG's rotor and grid side converters during network unbalance. IEEE Trans. Power Electron. 2008, 23, 1041-1049. 